\title{
Karingana ua Karingana: Mia Couto, um contador de histórias moçambicano ${ }^{1}$
}

\author{
Patrick Chabal \\ King's College London
}

\begin{abstract}
RESUMO: AO RESSALTAR A IMPORTÂNCIA DO "CONTO" NA OBRA DE MIA COUTO, O ARTIGO DEFENDE QUE MESMO SEUS ROMANCES SÃO DEVEDORES DA FÓRMULA DESENVOLVIDA COM SUCESSO NAS NARRATIVAS CURTAS. ASSOCIA-SE A DIMENSÃO DESSA MODALIDADE COM A EXPERIÊNCIA JORNALÍSTICA DO AUTOR E SEU CONHECIMENTO DAS TRADIÇÕES ORAIS MOÇAMBICANAS, DESTACANDO-SE QUE A NARRATIVA DO AUTOR MOÇAMBICANO, AO CULTIVAR A APROXIMAÇÃO COM A POESIA, SITUA-SE ENTRE ESCRITA E ORALIDADE, MODERNIDADE E TRADIÇÃO, FANTASIA E REALIDADE.
\end{abstract}

ABSTRACT: BY STRESSING THE IMPORTANCE OF THE "SHORT STORY" IN MIA COUTO'S WORK, THE ARTICLE ARGUES THAT HIS NOVELS MAKE USE OF THE SAME FORMULA WHICH IS DEVELOPED, SUCCESSFULLY, IN HIS SHORT NARRATIVES. THIS COMPREHENSIVE MODALITY IS ASSOCIATED WITH THE AUTHOR'S JOURNALISTIC EXPERIENCE, BESIDES HIS KNOWLEDGE OF MOZAMBICAN ORAL TRADITIONS. THE ARTICLE ALSO EMPHASIZES THAT THE NARRATIVE BY MIA COUTO, WHEN APPROACHING TO POETRY, SITUATED ITSELF BETWEEN WRITTEN AND ORAL, MODERNITY AND TRADITION, FANTASY AND REALITY.

PALAVRAS-CHAVE: MIA COUTO, CONTO, ROMANCE, TRADIÇÕES ORAIS, MODERNIDADE, POESIA.

KEYWORDS: MIA COUTO, SHORT STORY, NOVEL, ORAL TRADITIONS, MODERNITY, POETRY.

\footnotetext{
1 Título original em inglês: "Karingana ua Karingana: Mia Couto as a Mozambican story teller". Tradução de Sueli Saraiva.

A versão revista e ampliada deste artigo foi publicada sob o título "Mia Couto or the Art of Story Telling”. In Portuguese Literary and Cultural Studies, Volume 10, 2003.
} 
ja Couto não é apenas um escritor consagrado em seu próprio país, Moçambique, mas é igualmente reconhecido em todo o mundo de língua portuguesa, onde seus livros são vendidos em grande quantidade. Embora muito se tenha escrito sobre ele até agora, a chave de seu excepcional sucesso continua em grande parte inexplicada. Por que Mia Couto atrai tanto, especialmente os leitores que conhecem pouco ou nada sobre Moçambique ou a África? O que esses leitores veem numa prosa repleta de "moçambicanismos" e marcada de maneira tão forte por uma língua inventada?

O escritor começa sua trajetória literária como poeta e passa também a se dedicar ao romance, além de escrever algumas peças de teatro; mas quero destacar aqui as suas narrativas curtas, seus contos, pois eles representam, a meu ver, a essência de sua obra. Sem dúvida é nos contos que Mia Couto atinge o maior grau de originalidade literária, exibe a mais notável poeticidade, cria uma linguagem mais imaginativa e revela elementos psicológicos mais agudos. Nos contos este escritor moçambicano desenvolve um corpo de escrita, "cronicando" a evolução de seu país. Além disso, fica bastante evidente que mesmo seus romances são, pelo menos de certa forma, construídos segundo um "esquema de conto".

Escrever contos sempre foi uma arte bastante difícil, à qual poucos escritores contemporâneos têm se dedicado. Curiosamente, de uns tempos para cá esse passou a ser um gênero bastante experimentado em contextos nãoeuropeus - seja na América do Norte ou do Sul -, mais do que no continente onde o gênero floresceu no século XIX. Talvez esta seja hoje uma forma de expressão literária particularmente bem adaptada ao novo mundo, aos espaços fronteiriços, para além do império ou, mais ainda, uma forma cara à experiência pós-colonial. Talvez porque o conto seja um tipo de escrita que se mantém mais próximo à oralidade da vida cotidiana, sendo tal oralidade frequentemente característica das áreas "novas" ou "marginais".

Independentemente das razões que levam Mia Couto a escrever contos, eu gostaria de destacar aqui a importância da sua infância na Beira, onde seus pais se estabeleceram e onde ele nasceu, em 1955.2 Seu pai era jornalista e

2 Informações bibliográficas completas podem ser encontradas em: Laban, Michel. "Encontro com Mia Couto". In: Moçambique: Encontro com Escritores, vol. 3. Porto: Fundação Eng. António de Almeida, 1998; e na entrevista com o autor em: Chabal, Patrick. Vozes Moçambicanas: literatura e nacionalidade. Lisboa: Vega, 1994. 
escrevia poesia, e tanto se opunha ao regime de Salazar quanto se interessava pela vida dos africanos entre os quais a família vivia. Uma característica da infância de Mia Couto é particularmente importante. Seus pais não eram típicos colonos portugueses, isto é, eles não procuravam apenas ter uma existência "colonial", isolados da população local. Desde cedo Mia Couto viveu e interagiu com colegas de diferentes origens raciais e sociais, em especial com crianças negras e mestiças. Assim, ele cresceu em estreita proximidade com os africanos e embebeu-se de sua linguagem e tradições. O autor afirma:

... [R]ecordo-me das histórias que me eram contadas - quer em português, quer em chissena - pelos velhos e pelas pessoas que pertenciam a esse mundo, que transportavam esse outro imaginário. [...] [E]u ainda hoje volto muito a histórias que me foram contadas há muitos, muitos anos, das quais só me lembro de pedaços, de coisas que me assustavam, que me tiravam o sono como criança. ${ }^{3}$

Em 1983, Mia Couto publicou seu primeiro livro, Raiz de Orvalho, uma das primeiras coletâneas de poemas moçambicanos que se afastava da militância política, voltando-se para a expressão particular, intimista e subjetiva. O livro foi bem recebido, assim como os outros de mesmo viés literário publicados pela Associação dos Escritores Moçambicanos, na época uma das poucas saídas para a crescente literatura local.4 Couto e seus colegas de versos ( $\mathrm{Pa}$ traquim, Viegas, White, Baptista, Artur, Bucuane, Muteia e Saúte) seguiram os passos de uma geração de poetas moçambicanos notavelmente originais, entre eles os mais influentes foram sem dúvida José Craveirinha e Rui Knopfli. É natural, porém, que todos esses jovens quisessem revelar características próprias, que os diferenciassem de seus antecessores.

Mas o autor já havia começado a escrever obras em prosa curta, contos ou "estórias", a partir de seu interesse pelas histórias, fantasias ou assuntos variados da vida cotidiana que ia descobrindo durante o seu trabalho como jornalista e sendo influenciado pelas memórias de histórias contadas, remontando à sua infância. Seu primeiro livro em prosa, Vozes Anoitecidas, foi publi-

3 Laban, Michel. op. cit., p. 1011.

4 Vide Chabal, Patrick. "Mozambique". In Patrick Chabal. The Postcolonial Literature of Lusophone Africa. London: Hurst, 1996, p. 50-75. 
cado em Moçambique em 1986. Em 1988, é lançada uma coleção de crônicas semanais que ele havia escrito para o jornal Notícias nos dois anos anteriores. Ambos os livros foram muito bem recebidos em Moçambique e reeditados pela editora portuguesa Caminho, que hoje publica não somente toda a sua obra, mas também obras de outros autores moçambicanos como Suleiman Cassamo, Eduardo White, Ungulani Ba Ka Khosa e Paulina Chiziane. Mia Couto recebeu importantes prêmios por Vozes Anoitecidas, Cronicando e Terra Sonâmbula (seu primeiro romance). Sua fama literária tem crescido e, sem dúvida, tem ajudado a elevar o status da prosa moçambicana no mundo de língua portuguesa. ${ }^{5}$

Mia Couto publicou sete coletâneas de histórias curtas e cinco romances. ${ }^{6}$ Os primórdios de seus "contos" foram os textos de Cronicando, a compilação de algumas de suas crônicas jornalísticas. Como tal, o livro é um bom ponto de partida para o estudo de sua escrita um tanto fora do comum. Três características das crônicas logo se destacam, e todas estão no cerne de sua prosa subsequente. Elas têm a ver com a escolha de personagens, a maneira pela qual uma história é recontada e o desenvolvimento dos eventos de um modo altamente inesperado, irreal ou inusitado.

A primeira característica é a capacidade de focalizar personagens muito distintas, uma pessoa ou animal (reais ou inventados), seja pelo que são ou pela situação em que se encontram, ou ainda em função de seu comportamento. Todos os três aspectos são importantes e podem se sobrepor, pois o importante é chamar a atenção do leitor para um tipo, ou uma variedade, de personagens, que muitas vezes não apenas são estranhas, diferentes, mas também se comportam de uma forma muito peculiar. O fato é que tais personagens podem parecer normais, mas ao mesmo tempo se revelarem estranhas, ou serem claramente bizarras, irreais desde o início e mesmo assim se comportarem de modo claro e sensato. Seja qual for a situação, as personagens estão inevitavelmente associadas aos eventos, acontecimentos ou ações que ocorrem ao mesmo tempo dentro $e$ fora do campo da experiência humana comum, para além dos limites da vida cotidiana.

5 Em 1999, Mia Couto foi agraciado com a prestigiosa distinção literária portuguesa, o Prêmio Vergílio Ferreira, por sua contribuição à literatura em geral.

6 O autor está considerando as publicações efetuadas até o ano de 2002. (N. da T.) 
A marca característica da escrita de Mia Couto é, deste modo, a capacidade de apresentar tais personagens como se fossem perfeitamente normais, como se o que fazem, o que acontece com elas, fosse lógico em todos os sentidos. Em outras palavras, essas personagens não servem apenas para ilustrar o ponto a que se quer chegar, como seria o normal em qualquer conto, mas também, e talvez mais importante, para desafiar ou questionar os pressupostos e expectativas do leitor. Portanto, a grande originalidade dessa caracterização é a capacidade de retratar personagens aparentemente normais envolvidas em situações plausivelmente fantásticas.

O segundo traço distintivo da prosa coutiana é o modo pelo qual a história é contada. A rigorosa disciplina envolvida na escrita jornalística até certo ponto influenciou, ou melhor, condicionou desde o início o estilo do autor. Percebese, de forma implícita ou explícita, que para Mia Couto um conto é na prática uma obra limitada a um pequeno número de palavras. Embora outros contistas também publiquem narrativas curtas de ficção, elas tendem a ser na maioria das vezes escritas em extensões variadas. O notável no trabalho de Mia Couto é o tamanho padrão de quase todos os seus contos. Embora possa parecer uma coisa trivial, creio que isso seja de extrema importância; pois neste caso a escrita "medida" é uma das principais razões pelas quais os contos funcionam tão bem. A própria brevidade do gênero possibilita ao escritor uma concisão de expressão, no texto e no diálogo, que aguça a criatividade e eleva a imaginação.

O terceiro atributo é o final inesperado, ou a reviravolta na conclusão da história. De certa forma, esta é uma característica de todos os bons contos. Porém, Mia Couto tem aperfeiçoado a arte a um grau porventura desconhecido na literatura ocidental contemporânea e incomum até mesmo no chamado "realismo mágico" latino-americano. $\mathrm{Na}$ verdade, se poderia dizer que o aspecto mais original é o modo como o escritor encerra suas histórias (mais do que as conclui). É inegável o fato de Mia Couto elaborar os contos em torno de um final, visando encerrá-los de uma forma surpreendentemente inesperada. Este efeito é conseguido de várias maneiras diferentes, dependendo da escolha das personagens e do que lhes acontece; mas o fundamental é o elemento surpresa, ou paradoxal. Em grande medida as histórias de Mia Couto só revelam o que de fato são no último momento - e às vezes nem assim.

Para ilustrar o que quero dizer, devemos examinar mais de perto o primeiro texto de Cronicando, "A velha e a aranha", conforme a publicação moçambica- 
na (não a portuguesa). À primeira vista, trata-se da história de uma mãe esperando que seu filho retorne das tropas do exército. A frase de abertura resume o modo como Mia Couto cria uma disjunção fundamental, uma justaposição do real e irreal, do fato e da ficção, dentro de um cenário banal só na aparência:

Deu-se em época onde o tempo nunca chegou. Está-se escrevendo, ainda por mostrar a verdade caligrafada. [...] Uma mulher, oculta de face, entretinha suas vidas numa casinha tão pequena, tão mínima que se ouvia o roçar das paredes umas de encontro às outras. $\mathrm{O}$ antigamente ali se arrumava. [...] Sentada, imovente, a mulher presenciava-se sonhar. Naquela inteira solidão, ela via seu filho regressando. ${ }^{7}$

Este início não é apenas um modelo de concisão, mas também confere o tema: uma pessoa comum, em circunstâncias comuns, prestes a viver um evento extraordinário.

A velha, pressentindo que seu filho pode retornar a qualquer momento, se prepara para este acontecimento feliz vestindo a sua melhor roupa. De repente ela percebe uma teia de aranha sob o telhado e, intrigada, espera (muito tempo) que apareça o seu criador - que no fim é uma pequena aranha verde. A aranha exige silêncio, não quer ser incomodada. Ainda assim as duas "conversam” e chegam à conclusão que ambas estão à espera. A velha fica quieta por um (longo) período de tempo, até que, enfim, ouve passos de botas. A história, a bem dizer, se desenvolve "normalmente". Mas eis o modo como termina:

Encontraram a velha em estado de retrato, ao dispor da poeira. Em todo o seu redor, envolvente, uma espessa teia. Era como um cacimbo, a memória de um fumo. Ao seu lado, sem que se vislumbrasse entendimento, estava um par de botas negras, lustradas, sem gota de poeira.

A força da história está, conforme indiquei acima, no modo como os três aspectos do narrar [telling] se misturam. O que Mia Couto mais gosta de fazer, quando pode, é deixar a narrativa sem uma resolução óbvia, sem um fecha-

\footnotetext{
7 Mia Couto. Cronicando. Maputo, Publicações Notícias, 1988, p. 5-6. Escolhi esta história não porque ele seja "melhor" do que outras, mas simplesmente por ser a primeira [nesta edição]. Podemos muito bem supor que a escolha do autor ao colocá-la ali não seja irrelevante.
} 
mento simples. Para ele, um conto não é uma fábula, não é edificante, mas simbólico. Quanto a isso pelo menos, a sua escrita não é de fato derivada da tradição da oratura africana, que é quase sempre didática.

Eu não tentaria fazer aqui uma análise linguística da escrita de Mia Couto, uma iniciativa que exigiria um estudo muito mais sistemático do estado atual da língua portuguesa em Moçambique do que é possível num artigo.8 Gostaria, em vez disso, de deixar um pouco mais claro o modo como o autor cria a sua prosa, e fazer uma breve avaliação de suas indiscutíveis qualidades. É importante, neste ponto, fazer uma distinção entre os contos e os romances, pois de fato existem diferenças de estilo entre eles. E essas diferenças não devem ser omitidas. Apesar disso, o mais notável, do meu ponto de vista, é o quanto seus romances são escritos à semelhança dos contos. $\mathrm{Na}$ verdade, um estudo da sua obra em narrativa longa certamente destacaria ali as características linguísticas dos contos.

Os romances são divididos em um grande número de capítulos curtos (em geral). Cada capítulo apresenta algumas ou todas as características discutidas acima - em particular no que se refere às aberturas -, ainda que naturalmente o respectivo final leve em conta uma certa continuidade. Mas, uma vez que os contos, como já demonstramos, nunca são propriamente "concluídos", o paralelismo com os capítulos dos romances fica bastante evidente. Além disso, a construção do romance não é tanto cumulativa, ou mesmo linear, quanto é circular - isso quer dizer que não há um desenvolvimento da trama como tal, mas sim uma sequência de eventos, ou narrativas, que podem ou não ser "resolvidos" no final.

O que importa, e desta maneira os romances de Mia Couto são muito africanos, é o caminho percorrido e não o ponto de chegada. Isso é mais bem demonstrado no principal romance do autor, Terra Sonâmbula; sem dúvida, a obra em prosa emblemática do Moçambique pós-colonial, no auge da guerra civil. ' Mas isso também é notável em seus outros dois importantes

8 Sobre o português de Moçambique, vide Perpétua, Gonçalves. Português de Moçambique: Uma Variedade em Formação. Maputo: Universidade Eduardo Mondlane, 1996.

9 Couto, Mia. Terra Sonâmbula, Lisboa: Caminho, 1992. Para uma discussão deste importante romance, vide Gonçalves, Fiona. "Narrative Strategies in Mia Couto’s Terra Sonâmbula” [Estratégias narrativas em Terra Sonâmbula de Mia Couto]. In Current Writing: text and reception in Southern Africa, 7, 1, 1995, p. 60-69. 
romances, A Varanda do Frangipani e O Último Voo do Flamingo, onde os finais, mais uma vez, não dão uma sensação de conclusão. ${ }^{10}$

Terra Sonâmbula começa assim:

Naquele lugar, a guerra tinha morto a estrada (... A estrada que agora se abre a nossos olhos não se entrecruza com outra nenhuma. Está mais deitada que os séculos, suportando sozinha toda a distância... ${ }^{11}$

O primeiro parágrafo do segundo capítulo ${ }^{12}$ é ainda mais claro em sua relação com o estilo do conto:

Quero pôr os tempos, em sua mansa ordem, conforme esperas e sofrências. Mas as lembranças desobedecem, entre a vontade de serem nada e o gosto de me roubarem do presente. Acendo a estória, me apago a mim. No fim destes escritos, serei de novo uma sombra sem voz. ${ }^{13}$

E as últimas frases do livro:

... Me apetece deitar, me anichar na terra morna. [...] Mais adiante segue um miúdo com passo lento. Nas suas mãos estão papéis que me parecem familiares. Me aproximo e, com sobressalto, confirmo: são os meus cadernos. [...] Movidas por um vento que nascia não do ar mas do próprio chão, as folhas se espalham pela estrada. Então, as letras, uma por uma, se vão convertendo em grãos de areia e, aos poucos, todos meus escritos se vão transformando em páginas de terra. ${ }^{14}$

10 Couto, Mia. A Varanda do Frangipani, Lisboa: Caminho, 1996; _ O Último Voo do Flamingo, Lisboa, Caminho, 2000. Dedico menos atenção aqui ao romance encomendado, Vinte e Zinco (Lisboa: Caminho, 1999), pois me parece ter sido prejudicado em alguns aspectos, e em particular estilisticamente, por suas origens programáticas. Seu último romance, Mar me Quer (Lisboa: Caminho, 2000), é na minha opinião, melhor visto como um conto estendido. Ele é, de qualquer modo, mais parecido com A Varanda do Frangipani na construção, no estilo e na caracterização.

11 Terra Sonâmbula, p. 9.

12 Nas edições atuais, a passagem se encontra na narrativa intercalada "Primeiro Caderno de Kindzu", antes do início do segundo capítulo. (N. da T.)

13 Ibidem, p. 15.

14 Ibidem, p. 218 
O interessante sobre o final de Terra Sonâmbula é como ele é similar ao da maioria dos contos do autor. Não somente ele não é "possível", da perspectiva do que vinha acontecendo com as personagens principais do romance, como ele ainda é fantástico, no sentido em que converte o fictício em factual. Sobretudo, assim como ocorre nos contos, o romance não tem uma conclusão. As últimas linhas servem apenas para fechar o círculo, na medida em que sugerem uma continuação daquela dialética esquiva entre as palavras que produzem uma narrativa dos eventos e o chão que sustém o patrimônio cultural do país. O romance é uma crônica de uma tragédia que vai se desvelando. Ele serve para dar um sentido de viagem à deriva, na qual embarcaram os habitantes de uma terra aflita. Assim, tal qual nos contos, Terra Sonâmbula nos permite sentir em vez de buscar o sentido do que está acontecendo.

Sem dúvida, os romances de Mia Couto tratam de forma muito mais explícita a história de Moçambique independente e, deste modo, abordam de maneira muito mais direta do que os contos a questão da identidade do país e da calamidade de sua experiência pós-colonial. Mas é claro que eles também revelam a intenção de construir uma linguagem literária que dê conta dessa história dentro daquilo que se poderia designar de uma escrita culturalmente localizada. Por esta razão, os romances não são apenas uma expressão da complexa situação do país desde a independência, mas são, acima de tudo, a tentativa de fundamentar essa experiência num contexto local significativo isto é, um que esteja em consonância com as tradições e as crenças da maioria de seus habitantes. Assim, a prosa romanesca evidencia uma ambição muito maior, e tem como objetivo criar um corpo de escrita com um significado cultural que supere as diferenças entre as circunstâncias modernas, e mesmo pós-modernas, em que o país se encontra, e os fundamentos "tradicionais" dos quais as elites dominantes muitas vezes querem se distanciar.

Neste ponto, A Varanda do Frangipani não possui ambiguidade. Num primeiro plano, o romance enreda uma investigação sobre a morte do diretor de um asilo de idosos, mas na verdade trata-se de um grande discurso sobre o modo como a modernidade do país existe em detrimento de suas raízes culturais. O frangipani é o elo com o passado, e a investigação, de um modo previsível, não atinge os seus objetivos. Aqui, mais uma vez, o melhor a fazer é citar o último parágrafo do romance: 
Aos poucos, vou perdendo a língua dos homens, tomado pelo sotaque do chão. $\mathrm{Na}$ luminosa varanda deixo meu último sonho, a árvore do frangipani. Vou ficando do som das pedras. Me deito mais antigo que a terra. Daqui em diante, vou dormir mais quieto que a morte. ${ }^{15}$

Os internos, inclusive um velho português, decidem voltar para as raízes do frangipani, em vez de sofrer a loucura do mundo "real". A tradição vence a cegueira e a futilidade da modernidade. Como em Terra Sonâmbula, as últimas frases unem as palavras com o chão, como se fosse de fato a terra que abriga a "realidade" que vale a pena preservar.

Mas, $A$ Varanda do Frangipani também exemplifica a minha visão sobre a gênese dos romances de Mia Couto, pois se trata, sem dúvida, de um romance claramente construído como uma série de capítulos que seguem de perto os padrões estilísticos de suas narrativas curtas. Neste sentido, o romance é, de um modo quase literal, um conjunto de contos inter-relacionados que tratam dos personagens que surgem na história ou como residentes ou como vindos de fora do asilo. Ainda que o romance seja, é óbvio, mais do que um simples apanhado de narrativas isoladas, o que o torna tão atraente é o modo bastante peculiar (em termos de literatura contemporânea) como a narrativa é construída por seções independentes e circulares. O artifício é o depoimento aparentemente simples e direto de cada uma das personagens sobre a morte do diretor. Na verdade, cada capítulo é a história de uma vida recontada, tanto em fatos quanto em fantasia, por aqueles que rejeitam uma explicação objetiva, moderna e "externa" para suas vidas.

Isso nos leva de volta aos contos. Se nos romances Mia Couto está preocupado em dar testemunho da história de Moçambique à medida que ela vai acontecendo, nos contos o ficcionista se permite total liberdade. Em suas próprias palavras, ele não procura as histórias, elas vêm até ele:

Olha, as pessoas que convivem comigo, constroem as histórias que me vêm contar. Episódios que veem no meio da rua e me vêm dar o instrumento que é o material para fazer depois um trabalho que é um trabalho de artesanato.16

15 A Varanda do Frangipani, p. 152

16 Vozes Moçambicanas, p. 290 (itálicos no original). 
Esta questão é muito importante, pois explica porque os contos apresentam esse claro diferencial. É o fato de virem do mundo "real" que toca o autor, e este, por sua vez, os torna originais e cativantes. É quase como se não pudessem ser inventados, pois a realidade é muito mais estranha que a ficção. Os romances, em contrapartida, são construídos, a meu ver, com uma intenção mais clara de representar na literatura a grande narrativa do país. E, embora sigam o mesmo estilo dos contos, a sua ambição e extensão os tornam menos "espontâneos" ou vívidos.

Assim, uma qualidade inquestionável dos contos é o estranhamento imediato, esse sentimento poderoso que eles materializam "do nada". O que não significa que não tenham sido escolhidos e elaborados de forma meticulosa, mas ocorre tão somente porque, em geral, eles operam totalmente de modo a confundir as expectativas tranquilas, implícitas e, talvez, preguiçosas, do leitor. Um segundo aspecto de sua originalidade é a coerência absoluta no entrelaçamento de fato e ficção, realidade e fantasia. Isso não é alcançado, como ocorre em outros escritos (por exemplo, alguns da literatura realista mágica, ou mesmo pós-moderna), pela sobreposição forçada do real e do inventado, de modo que a distinção entre os dois ainda seja percebida. Ao contrário, essa coerência absoluta resulta da interpretação de uma realidade que se mostra bastante "objetiva" e que por acaso é uma mistura do factual e do ficcional.

Por outro lado, a importância dessa construção literária não está somente na exploração dos efeitos alcançados por esse tipo de disparidade. É bem o oposto: o frescor da escrita de Mia Couto reside precisamente nessa mistura que compõe a vida "genuína" das histórias. Enquanto em escritores contemporâneos "pós-modernos", como, por exemplo, Rushdie, o contraste é com frequência posto em jogo para impressionar, em Mia Couto não existe essa intenção: é como dizer de forma simples e objetiva que a vida é uma combinação inexplicável de fatos e fantasia. Portanto, o que torna suas histórias tão vívidas é o modo como elas atraem o leitor para um mundo tão real quanto qualquer outro, onde as fronteiras são postas em causa, quando não de todo apagadas. ${ }^{17}$

17 Para uma discussão sobre Mia Couto como um escritor pós-moderno, vide Rothwell, Phillip. A Postmodern Nationalist: truth, orality and gender in the work of Mia Couto; e Lisboa, Maria Manuela. Colonial Crosswords: (in)voicing the gap in Mia Couto. In Fiddian, Robin, Postcolonial Perspectives on the Cultures of Latin America and Lusophone Africa. Liverpool: Liverpool University Press, 2000, p. $190-212$. 
Quase todas as histórias demonstram essa característica, mas, para esclarecer melhor meu argumento, vou mencionar uma que o próprio Mia Couto afirma despertar nele o desejo de escrever deste modo. Segundo o autor, é na tradição local de contar histórias que ele primeiramente encontra inspiração. Ao falar sobre a sua primeira tentativa de escrever tal história, publicada mais tarde como "As Baleias de Quissico", ele explica:

E, à medida que eu ia fazendo, eu me apercebi que não podia usar o português clássico, a norma portuguesa, para contar a história com toda a carga poética que ela tinha. Era preciso recriar uma linguagem que trouxesse aquele ambiente de magia em que a história me foi contada. E aí começa essa experiência e, interessantemente, eu fui de repente projectado para a infância, para os tais momentos de que falo, em que os tais velhos contavam as tais histórias. [...] E isso [contar história] só é possível através de, número um, a poesia e, número dois, uma linguagem que utilize este jogo de dança e de teatro que eles faziam. Então foi aí que eu comecei, de facto, a experimentar os limites da própria língua e a transgredir no sentido de criar um espaço de magia. ${ }^{18}$

A chave para as origens de sua pesquisa estilística, portanto, reside na busca por uma forma de expressar o fantástico na vida cotidiana por meio da "prosa" poética. Não existe em seu pensamento, como ele próprio sublinhou, nenhuma distinção válida entre as duas formas de expressão literária:

A única coisa que eu posso dizer é que eu estou tentando criar [...] beleza, mostrar um pouco o que é a possibilidade de alguém fazer uma língua sua. De criar a partir da desarrumação daquilo que é o primeiro instrumento de criação, que seria a língua, a linguagem, e os modelos de uma narrativa. Por exemplo, abolir esta fronteira entre poesia e prosa. Porque é que a coisa tem que estar arrumada, porque é que é preciso haver esta categorização de géneros literários, [...] o realismo mágico, o realismo neo-realista? Nos podemos talvez criar à margem disso. ${ }^{19}$

18 Laban, op. cit., pp. 1015-1016 (grifos nossos).

19 Vozes Moçambicanas, p. 289. 
Embora seja o caso muitas vezes de as declarações dos escritores sobre o seu próprio trabalho não serem esclarecedoras, acredito que Mia Couto oferece aqui uma visão genuína da sua escrita - como é muito fácil de comprovar por meio de uma leitura sensível, em vez da simples análise linguística de seus contos.

Há várias formas muito sutis que indicam o enraizamento de sua narrativa na cultura dentro da qual ele vive. Destas, eu gostaria de destacar apenas três: linguagem, personagem e estrutura. Mia Couto é famoso, com toda justiça, por ter criado um espaço linguístico em que é possível representar de forma literária o tom, a cadência e a composição da língua falada em Moçambique (pelo menos nas áreas urbanas). Isso não significa que ele reproduza o modo, ou modos, como as pessoas se expressam na realidade, como Suleiman Cassamo faz numa proporção muito maior. Trata-se, para ser mais exato, da evocação que ele faz da musicalidade e teatralidade associadas a essas características, tais como são encontradas na língua portuguesa falada pelas pessoas comuns. Sua prosa está em perfeita sintonia com o que eu chamaria de "maneirismos", aquela forma de expressão viva que torna possível a comunicação, e também os mal-entendidos, entre os moçambicanos. Mia Couto tem um ouvido extraordinariamente aguçado, não apenas para as expressões concretas que se ouvem todos os dias nas ruas de Maputo, mas também para as excentricidades linguísticas de uma língua feita de misturas inesperadas do português colonial e dos vernáculos locais. É somente neste contexto, creio, que ele teria seguido o exemplo de Guimarães Rosa. ${ }^{20}$

A segunda característica que eu gostaria de destacar diz respeito aos personagens. Como é óbvio para quem já está familiarizado com seus livros, Mia Couto habita um mundo de criaturas maravilhosamente "simples", mas de extrema força evocativa. Não se supõe que pudéssemos de fato conhecer alguma delas, mas todas logo se tornam familiares - como se tivéssemos vivido sempre ao lado delas sem, contudo, percebê-las. A questão não é já termos encontrado ou conhecido tal pessoa em Moçambique ou em outro lugar numa situação real. $O$ fato é que essas personagens são notáveis por sua humanidade, uma característica que nos é importante e que as torna tão palpáveis. O que une essa caracterização ao contexto local é o infalível olhar

20 Aqui, ver Mary Daniel, 1995, "Mia Couto: Guimarães Rosa's newest literary heir in Africa". LusoBrazilian Review, 32, 1 (Summer), pp. 1-16. 
de Mia Couto para o comportamento das personagens. Como um pintor, ele capta o que é revelador em pequenas personalidades, e o quadro que ele nos oferece - pois é isso o que as narrativas realmente são - nos faz sentir, e não apenas interpretar, como as pessoas em Moçambique podem estar vivendo suas vidas; mas que de um modo geral elas não percebem completamente. É uma verdade inquestionável que o escritor pode ter desenvolvido esse tipo de caracterização sensível devido em parte à sua assimilação da cultura africana. No entanto, argumentar que a sua prosa simplesmente segue os modelos da literatura oral seria diminuir em muito a sua arte.

A única área onde talvez o autor tenha sido mais fortemente influenciado pela literatura africana é na sua estrutura narrativa. $O$ autor habita um ambiente cuja predominância é a oralidade (ainda que um número cada vez maior de moçambicanos já possa ler e escrever), não apenas por ser africano, mas porque enquanto ficcionista ele escolheu se dedicar a personagens que vivem justamente neste meio social. Seu interesse não são as classes médias educadas, letradas, mas os homens e mulheres comuns, cuja existência raramente é captada pelos escritores de ficção. Mia Couto reconhece a sua dívida com a tradição africana de contar histórias, e fica claro que ele continua a tratar com o maior interesse o modo como as pessoas lidam com suas vidas, na realidade e na fantasia. Sua alegação de que extrai as histórias daquilo que ouviu pode soar um tanto artificial, no entanto deve ser entendida simplesmente como uma afirmação do óbvio. Inspiração não é o mesmo que imitação. $\mathrm{Na}$ medida em que Mia Couto tem a intenção de "contar" histórias, é claro que a construção de sua obra se inspira na arte de contar histórias que lhe é mais familiar - aquela de Moçambique.

No final das contas, porém, é inútil procurar estabelecer em que medida a obra do autor é ou não é africana e, se for, como. A questão em si é supérflua. Mia Couto é um moçambicano e não existe qualquer razão para supor que a cor de sua pele ou sua ascendência portuguesa seja um empecilho para que ele retrate a cultura em que cresceu. Como ele mesmo diz: "O que eu escrevo é moçambicano, digamos inconscientemente, involuntariamente. Eu não faço nenhuma coisa para que seja. É uma maneira, simplesmente, entre mil outras". ${ }^{21}$ É evidente que o autor escreve sobre o país, o povo e a sociedade

21 Vozes Moçambicanas, p. 290. 
que ele conhece melhor - como fazem todos os escritores. Seja qual for a influência que as tradições literárias africanas possa ter tido sobre ele, isso não explica por que seus livros são tão bem sucedidos. Isso apenas ajuda a situálos no contexto histórico e cultural adequado. ${ }^{22}$

O que faz de Mia Couto um escritor inovador é o fato de ele conseguir mesclar uma percepção única das pessoas comuns de seu país com um estilo de narrativa imaginativa. Sua proeza não está nas invenções linguísticas ou nas fontes de inspiração, mas num sentido de poeticidade finamente sintonizado e dedicado a revelar a absoluta humanidade de pessoas cujas vidas ele compartilhou desde criança. É dele verdadeiramente uma arte original de contar histórias.

22 Sobre a muito debatida questão da "moçambicanidade", ver Gilberto, Matusse. A Construção da Imagem de Moçambicanidade em José Craveirinha, Mia Couto e Ungulani Ba Ka Khosa, Maputo, Universidade Eduardo Mondlane, 1998. 